\title{
Radiation Risks of Kidney during Abdominal CT Procedures in Morocco: A Multicentre Study
}

\author{
Bouchra Amaoui ${ }^{*}$, Slimane Semghouli ${ }^{2}$, Fatima Safini ${ }^{3}$, Abdelmajid Choukri ${ }^{4}$ \\ ${ }^{1}$ Faculty of Medicine and Pharmacy, Ibn Zohr University, Agadir, Morocco \\ ${ }^{2}$ Higher Institute of Nursing Professions and Health Techniques, Agadir, Morocco \\ ${ }^{3}$ Regional Center of Oncology, Agadir, Morocco \\ ${ }^{4}$ Materials and Subatomic Physics Laboratory, University of Ibn Tofail, Kenitra, Morocco \\ Email: ^b.amaoui@uiz.ac.ma
}

How to cite this paper: Amaoui, B., Semghouli, S., Safini, F. and Choukri, A. (2021) Radiation Risks of Kidney during Abdominal CT Procedures in Morocco: A Multicentre Study. Journal of Biosciences and Medicines, 9, 86-93.

https://doi.org/10.4236/jbm.2021.95009

Received: April 5, 2021

Accepted: May 23, 2021

Published: May 26, 2021

Copyright (c) 2021 by author(s) and Scientific Research Publishing Inc. This work is licensed under the Creative Commons Attribution International License (CC BY 4.0).

http://creativecommons.org/licenses/by/4.0/

\begin{abstract}
This study aimed to estimate renal effective dose during abdominal CT scans in order to assess the renal risks of cancer and heredity per procedure in Moroccan hospitals. It's consisted of examining a total of 120 patients referred to three radiology departments for an abdominal CT scan at the rate of 40 per hospital. The data that collected for this diagnostic exam included scanner acquisition parameters, number of series, use of the contrast medium, and rotation time as well as slice thickness, the displayed CT dose index $\left(\mathrm{CTDI}_{\mathrm{vol}}\right)$ and the Dose Length Product (DLP). Renal dose, effective dose and biological risks were estimated using the International Commission on Radiological Protection (ICRP) conversion factor. The patients included in this study were an average age of the $(46.49 \pm 14.16)$ years and an average weight of $(73.34 \pm$ $7.58) \mathrm{kg}$. For the mean effective dose $(E)$ and average kidney dose $\left(D_{K}\right)$ received per patient during an abdominal CT scan, it were respectively of (6.67 $\pm 2.73)$ and $(18.26 \pm 7.74) \mathrm{mSv}$. The distribution of these values according to the hospital variable shows a difference in mean effective dose of the order of $0.26,0.38$ and $1.45 \mathrm{mSv}$ and a difference in the mean renal dose of the order of 8.76, 4.94 and $0.48 \mathrm{mSv}$ respectively for $\mathrm{H} 1, \mathrm{H} 2$ and $\mathrm{H} 3$. The induction cancer risk of abdominal and kidney per $10^{5}$ procedures was respectively of 3 and 10. The kidney cancer risk by procedure is two to three times more likely than abdominal. For hereditary risk of abdominal and renal exposure per $10^{6}$ procedures, it is 14 and 21 respectively. The renal stochastic effect by procedure is also two to three times more likely than that of the abdomen. Our values are relatively higher than those of published in some previous studies. Cancer risk and heredity estimation highlights the need to limit radiation dose. This first ever survey confirmed the need to improved training of health professionals involved in computed tomography on factors affecting image
\end{abstract}


quality, doses and protocols optimization.

\section{Keywords}

Abdominal CT Scans, Effective Renal Dose, Cancer and Heredity Risks

\section{Introduction}

Medical imaging is a valuable and indispensable tool for the detection, diagnosis and efficient control of many diseases. Every year, approximately 3.6 billion diagnostic radiology procedures are performed worldwide [1]. Exposure to X-rays during imaging procedures can generate biological effects. Ionizing radiation can cause cell death by apoptosis or failure of induced reproduction, which can lead to changes in genes involved in the regulation of cell growth, loss of normal nuclear structure, DNA degradation and tumorigenesis [2]. These effects include cancer and hereditary effects, which increase an individual's lifetime risk of developing cancer or hereditary effects in future generations. Tissue response effects have specific threshold doses inducing radiological risks at relatively high doses [3]. The International Commission on Radiological Protection (ICRP) has adjusted the nominal radiological detriment coefficients for cancer and hereditary effects as follows: $5.5 \times 10^{-2}$ and $0.2 \times 10^{-2} \mathrm{~Sv}^{-1}$ for the whole population [3]. In addition to these effects, radiation exposure is associated with certain diseases (non-cancer effects), such as respiratory diseases, stroke, heart disease and digestive disorders [3] [4]. Although the radiological risks of non-cancerous diseases at low doses remain uncertain, doses delivered should be kept at minimum values to ensure patient protection [2] [3].

Chronic kidney disease is a real public health problem worldwide, economically, medically, and socially. It affects about $3 \%$ of the Moroccan population [5]. The multi-detector scanner is the reference imaging modality for urothelial tumor assessment thanks to its excellent spatial and temporal resolution [6] [7]. It allows the analysis of the renal parenchyma at the different phases of its development as well as the secretion of contrast agents in the urinary cavities. As a result, patient care has been significantly improved by accurate diagnosis of urinary system disorders compared to other imaging modalities. Repeated exposure of the kidneys during certain CT scans increases the effective dose received by this organ. However, CT procedures present a radiogenic risk due to the high doses delivered during image acquisition, which depends on age, gender and health status [8]. Previous studies have estimated that 1.5\% - 2\% (29,000 cancer cases) of cancers diagnosed each year in the United States are associated with CT scan exposure [4] [9].

In Morocco, the scarcity of studies on exposure to ionizing radiation during medical examinations of the population [10] [11] and on the establishment of diagnostic reference levels [12] [13] [14] [15] [16] has led us to explore the exposure of the kidneys during CT examination of the abdomen. 
The objective of this study was to evaluate the effective dose of the CT scan examination as well as the renal dose in order to estimate the likely biological effects of such exposure.

\section{Materials and Methods}

\subsection{Data Collection}

This is a prospective study that was conducted in three Moroccan hospitals. A sample of 120 adult patients referred for a CT scan of the abdomen was collected at a rate of 40 patients per radiology department. For each patient we collected these demographic data as well as exposure parameters $\left(\mathrm{kV}, \mathrm{mAs}\right.$, Pitch, $\mathrm{CTDI}_{\mathrm{vol}}$, DLP etc.) on the console of a Philips CT scanner with 2 slices for the hospital H1, a GE CT scanner with 16 slices for the hospital H2 and a Toshiba CT scanner with 64 slices for the hospital H3.

The effective dose and renal dose were estimated according to the recommendations of the International Commission on Radiological Protection [3]. The formulas below were used:

$$
D_{\text {eff }}(\mathrm{mSv})=0.0152 \times \mathrm{DLP}
$$

with:

- $\quad D_{\text {eff: }}$ The effective dose received per patient for a given CT scan.

- DLP: Dose length product for a given scan examination.

$$
D_{\text {kidney }}(\mathrm{mSv})=0.0086 \times \mathrm{CTDI}_{w} \times \mathrm{mAs}
$$

with:

- $\quad D_{\text {kidney }}:$ Renaldose received per patient for a given CT scan.

- CTDI $_{w}$ Computed Tomography Dose Index weighted.

- mAs: Load for a given CT scan.

\subsection{Cancer and Hereditary Risks Assessment}

The overall cancer risk per procedure was obtained by multiplying the effective dose per Sievert (Sv) by the coefficient $5.5 \times 10^{-2} \mathrm{~Sv}^{-1}$ according to the ICRP 103 formalist [3].

The risk for hereditary diseases up to the second generation per procedure was estimated by multiplying the effective dose expressed in Sievert (Sv) by the coefficient $0.2 \times 10^{-2} \mathrm{~Sv}^{-1}$ according to ICRP 103 [3].

\section{Results}

Data from 120 patients referred for a CT scan of the abdomen were collected from 40 patients per radiology department in the three hospitals involved in the study. Table 1 includes age, weight, exposure parameters $(\mathrm{kV}, \mathrm{mAs})$ as well as dosimetry parameters $\left(\mathrm{CTDI}_{\mathrm{vol}}\right.$, DLP) for the abdominal procedures performed.

The age of the patients included in this study varies between $(41.00 \pm 11.56)$ and $(52.15 \pm 19.38)$ with a mean value of $(46.49 \pm 14.16)$ years. For their weight, it varies between $(71.44 \pm 7.71)$ and $(76.31 \pm 6.84)$ with a mean value of $(73.34 \pm$ 
Table 1. The mean and range values for Age, Weight, $\mathrm{kVp}$, and $\mathrm{mAs}$ and for all the abdominal procedures and per Hospital.

\begin{tabular}{ccccccc}
\hline Hospital & Age $\pm \mathrm{SD}(\mathrm{y})$ & Weight $\pm \mathrm{SD}$ & $\mathrm{kVp} \pm \mathrm{SD}$ & $\mathrm{mAs} \pm \mathrm{SD}$ & $\mathrm{CTDI}_{\mathrm{vol}} \pm \mathrm{SD}$ & $\mathrm{DLP} \pm \mathrm{SD}$ \\
\hline All Hospitals & $46.49 \pm 14.16$ & $73.34 \pm 7.58$ & $119.81 \pm 4.15$ & $154.96 \pm 41.83$ & $10.89 \pm 4.77$ & $438.73 \pm 179.93$ \\
H1 & $52.56 \pm 11.75$ & $76.31 \pm 6.84$ & $120.00 \pm 0.00$ & $212.81 \pm 21.98$ & $17.04 \pm 3.07$ & $456.82 \pm 237.72$ \\
H2 & $41.00 \pm 11.56$ & $71.44 \pm 7.71$ & $120.00 \pm 0.00$ & $120.00 \pm 0.00$ & $7.38 \pm 2.85$ & $407.76 \pm 181.29$ \\
H3 & $52.15 \pm 19.38$ & $73.31 \pm 7.25$ & $119.23 \pm 8.62$ & $150.77 \pm 11.15$ & $10.96 \pm 2.37$ & $518.29 \pm 140.81$ \\
\hline
\end{tabular}

7.58) $\mathrm{kg}$. To study the effect of these variations on the dose results, the sample $\mathrm{P}$-value correlation coefficient was calculated between weights, $\mathrm{CTDI}_{\mathrm{vol}}$ and DLPs for all examinations. It is 0.08 and $<0.01$ for weight vs $\mathrm{CTDI}_{\mathrm{vol}}$ and weight vs DLP, respectively.

For the exposure parameters, the voltage applied in the three hospitals is almost the same $\approx 120 \mathrm{kV}$ and the current varies between 120 and 213 with an average value of $155 \mathrm{mAs}$. For dosimetric parameters, $\mathrm{CTDI}_{\mathrm{vol}}$ per sequence varies between 7.38 and $17.04 \mathrm{mGy}$ with a mean value of $10.89 \mathrm{mGy}$ and DLP per examination varies between 407.76 and 518.29 with a mean value of 438.73 mGy.cm.

The effective dose $(E)$ received per patient during an abdominal CT scan varies between $(6.29 \pm 2.75)$ and $(8.12 \pm 1.83) \mathrm{mSv}$ with a mean value of $(6.67 \pm$ 2.73) $\mathrm{mSv}$. While the renal dose $\left(D_{K}\right)$ varies between $(13.32 \pm 5.15)$ and $(26.99 \pm$ 6.07) $\mathrm{mSv}$ with a mean value of $(18.26 \pm 7.74) \mathrm{mSv}$ (Table 2$)$. The distribution of these values according to the hospital variable shows a difference in mean effective dose of the order of $0.26,0.38$ and $1.45 \mathrm{mSv}$ and a difference in mean renal dose of the order of $8.76,4.94$ and $0.48 \mathrm{mSv}$ for $\mathrm{H} 1, \mathrm{H} 2$ and $\mathrm{H} 3$ respectively. However, the ANOVA test showed a significant difference between the three hospitals in terms of effective dose $(\mathrm{F} E(\mathrm{mSv})=20.10 ; \mathrm{p} \leq 0.01)$ and not significant in terms of renal dose $\left(\mathrm{F} D_{k}(\mathrm{mSv})=2.17 ; \mathrm{p}=0.119\right)$.

The effective dose $E(\mathrm{mSv})$ and the renal dose $D_{k}(\mathrm{mSv})$ received per patient during the CT scan of the abdomen can cause biological effects. The risk of induction of abdominal and kidney cancer is 3 to 4 and 7 to 13 per $10^{5}$ procedures, respectively (Table 3 ). Kidney cancer per procedure is two to three times more likely than abdominal cancer. For the hereditary risk of abdominal and renal exposure, it is 12 to 16 and 27 to 54 per $10^{6}$ procedures, respectively. The kidney stochastic effect per procedure is also two to three times more likely than that of the abdomen. However, the ANOVA test showed a non significant difference between the three hospitals in terms of carcinogenic risk ( $\mathrm{F}$ kidney cancer risk $=$ 1.97; $\mathrm{p}=0.145 ; \mathrm{F}$ CT cancer risk $=0.497 ; \mathrm{p}=0.609$ ) and stochastic risk (F kidney hereditary risk $=1.382 ; \mathrm{p}=0.257 ; \mathrm{F}$ CT hereditary risk $=1.211 ; \mathrm{p}=0.303$ ).

\section{Discussion}

The average body weight of patients in the three hospitals included in the study ranged from $(71.44 \pm 7.71) \mathrm{kg}$ to $(76.31 \pm 6.84) \mathrm{kg}$. This shows that the patients weighed more than $60 \mathrm{~kg}$ considered as average weight for Asian and African 
Table 2. The mean, range, median, and for the effective dose $E$ and kidney dose $D_{K}(\mathrm{mSv})$ for all procedures and per hospital.

\begin{tabular}{ccccc}
\hline Hospital & \multicolumn{2}{c}{$E(\mathrm{mSv})$} & \multicolumn{2}{c}{$D_{K}(\mathrm{mSv})$} \\
\hline & Mean $\pm \mathrm{SD}$ & Range & Mean \pm SD & Range \\
\hline All Hospitals & $6.67 \pm 2.73$ & $3.27-12.09$ & $18.26 \pm 7.74$ & $4.08-35.69$ \\
H1 & $6.40 \pm 3.00$ & $4.20-12.09$ & $26.99 \pm 6.07$ & $21.97-35.79$ \\
H2 & $6.29 \pm 2.75$ & $3.27-11.37$ & $13.32 \pm 5.15$ & $8.07-23.13$ \\
H3 & $8.12 \pm 1.83$ & $4.31-9.80$ & $17.78 \pm 4.12$ & $6.24-23.64$ \\
\hline
\end{tabular}

Table 3. Cancer and hereditary risks per abdominal CT procedure and per hospital.

\begin{tabular}{|c|c|c|c|c|}
\hline \multirow[t]{2}{*}{ Hospital } & \multicolumn{2}{|c|}{ Abdominal CT } & \multicolumn{2}{|c|}{ Kidney } \\
\hline & $\begin{array}{c}\text { Cancer Risk per } 10^{5} \\
\text { procedures }\end{array}$ & $\begin{array}{c}\text { Hereditary Risk } \\
\text { per } 10^{6} \text { procedures }\end{array}$ & $\begin{array}{c}\text { Cancer Risk per } 10^{5} \\
\text { procedures }\end{array}$ & $\begin{array}{c}\text { Hereditary Risk } \\
\text { per } 10^{6} \text { procedures }\end{array}$ \\
\hline All Hospitals & 33 & 13 & 91 & 36 \\
\hline $\mathrm{H} 1$ & 32 & 13 & 135 & 54 \\
\hline $\mathrm{H} 2$ & 31 & 12 & 67 & 27 \\
\hline $\mathrm{H} 3$ & 39 & 16 & 89 & 35 \\
\hline
\end{tabular}

countries and $70 \mathrm{~kg}$ for developed countries [17]. This may also partly explain the slightly higher CT dose index (CTDI) values than those obtained by Shirazu et al. 2017 [18]. Differences in collected patient weights could influence the calculated effective doses due to the correlation found between weights and Dose Length Product (DLP) values $(\mathrm{p}<0.01)$ and not renal doses $(\mathrm{p}=0.08)$.

For exposure factors, the applied tube tension is almost the same for all three hospitals. It varies between $(119.23 \pm 8.62)$ and $(120.00 \pm 0.00) \mathrm{kVp}$ with a mean value of $(119.81 \pm 4.15) \mathrm{kVp}$, corresponding to the trends seen in most previous studies [17] [19]. On the other hand, the current applied per procedure varies between $(120.00 \pm 0.00)$ and $(212.81 \pm 21.98) \mathrm{mAs}$ with a mean value of $(154.96$ $\pm 41.83) \mathrm{mAs}$. These values are comparable to those reported by Sulieman et al. 2020 [19].

Analysis of abdominal image data from the three hospitals showed that the mean value of the CTDI $\mathrm{I}_{\mathrm{vol}}$ was between $(7.38 \pm 2.85)$ and $(17.04 \pm 3.07) \mathrm{mGy}$ with a mean value of $(10.89 \pm 4.77) \mathrm{mGy}$. The latter is almost twice as high as that reported by Shirazu et al. 2017 [18]. It is also higher than that recommended by the ICRP [3]. The mean DLP was $(438.73 \pm 179.93) \mathrm{mGy} . \mathrm{cm}$ with a minimum value recorded as $(407.76 \pm 181.29) \mathrm{mGy} . \mathrm{cm}$ and maximum value recorded as $(518.29 \pm 140.81) \mathrm{mGy} . \mathrm{cm}$. It was lower than the value found by Shirazu et al. 2017 (935.5 mGy.cm) and also lower than that recommended by International Commission on Radiological Protection (ICRP) Publication 103 (780 mGy.cm) [3] [18]. In addition, about 7\% of the DLPs were above the ICRP recommended doses [3].

The effective dose calculated from the DLP using the conversion factor of 
ICRP Publication 103 shows a variation from a minimum of $(6.29 \pm 2.75) \mathrm{mSv}$ to a maximum of $(8.12 \pm 1.83) \mathrm{mSv}$ with an average value of $(6.67 \pm 2.73) \mathrm{mSv}$. Renal dose was also estimated using ICRP Publication 103 as for effective dose. The calculated mean renal dose was $(18.26 \pm 7.74) \mathrm{mSv}$ with $(26.99 \pm 6.07) \mathrm{mSv}$ and $(13.32 \pm 5.15) \mathrm{mSv}$ as the maximum and minimum values recorded at $\mathrm{H} 2$ and $\mathrm{H} 1$ hospital respectively. It should be noted that all renal doses obtained exceeded the ICRP and EC recommended value of $12 \mathrm{mSv}$ [3]. However, the renal dose can be up to about three times that proposed by the ICRP and the EC [3]. This higher value can be explained by the broad parameters used by the scanning procedure pitch $\approx 1.75$ and load $=154 \mathrm{mAs}$ which were greater than 1.00/100 mAs and 0.813/75 mAs used by Salama et al. 2017 and Shirazu et al. 2017, respectively [17] [18]. For the effective dose, all our values are lower than the value obtained by Shirazu et al. 2017 and that recommended by the ICRP and the EC [3] [18].

\section{Conclusion}

The assessment of the effective and renal doses for 120 abdominal CT scan examinations in three different Moroccan hospitals allowed us to characterize the biological risks of exposure. The results obtained show a wide variation in exposure parameters and exposure doses during abdominal CT scans from one hospital to another. Even so, the average effective dose was generally lower than that recommended by the International Commission on Radiological Protection. This may not be sufficient, as some of the individual renal doses exceed the recommended values by up to $300 \%$, which can lead to a consequent prognosis. We therefore recommend the establishment of the national diagnostic reference level for the CT scan examination of the abdomen and also the training of our clinicians on the radiation protection of the patient.

\section{Acknowledgements}

We express our gratitude and thanks to the staff of the radiology departments of the three hospitals for their help during collection of data.

\section{Conflicts of Interest}

The authors declare that they have no conflicts of interest regarding the publication of this article.

\section{References}

[1] IAEA Bulletin (2017) Nuclear Techniques in the Field of Human Health Prevention, Diagnosis and Treatment. 1-32.

[2] Shah, D.J., Sachs, R.K. and Wilson, D.J. (2012) Radiation-Induced Cancer: A Modern View. The British Journal of Radiology, 85, e1166-e1173. https://doi.org/10.1259/bjr/25026140

[3] ICRP (2007) The 2007 Recommendations of the International Commission on Ra- 
diological Protection. ICRP Publication 103. Annals of the ICRP, 37, 1-332.

[4] Brenner, D.J. and Hall, E.J. (2007) Computed Tomography: An Increasing Source of Radiation Exposure. The New England Journal of Medicine, 357, 2277-2284. https://doi.org/10.1056/NEJMra072149

[5] Chrifi, A. (2019) Advanced and Terminal Chronic Kidney Disease Registry. Thesis in Medicine, Faculty of Medicine and Pharmacy, Sidi Mohamed Ben Abdellah University, Fes.

[6] Pfister, C., Roupret, M., Neuzillet, Y., Larre, S., Pignot, G., Quintens, H., et al. (2013) Recommandations du CCAFU 2013: Tumeurs de la voies excrétrice supérieures. Progrès en Urologie, 23, S126-S132. https://doi.org/10.1016/S1166-7087(13)70050-2

[7] Roupret, M., Babjuk, M., Comperat, E., Zigeuner, R., Sylvester, R., Burger, M., et al. (2013) European Guidelines on Upper Tract Urothelial Carcinomas: 2013 Update. European Urology, 63, 1059-1071. https://doi.org/10.1016/j.eururo.2013.03.032

[8] ICRP (2007) Managing Patient Dose in Multi-Detector Computed Tomography (MDCT). ICRP Publication 102. Annals of the ICRP, 37, 1-79.

[9] Berrington de Gonzalez, A., Mahesh, M., Kim, K.P., et al. (2009) Projected Cancer Risks from Computed Tomography Scans Performed in the United States in 2007. Archives of Internal Medicine, 169, 2071-2077.

https://doi.org/10.1001/archinternmed.2009.440

[10] Semghouli, S., Amaoui, B. and Maamri, A. (2015) Estimated Radiation Exposure from Medical Imaging for Patients of Radiology Service of Al Faraby Hospital, Oujda Morocco. International Journal of Cancer Therapy and Oncology, 3, 3325. https://doi.org/10.14319/ijcto.33.25

[11] Amaoui, B., Semghouli, S., El Kharras, A., El Fahssi, M., Hakam, O.K. and Choukri, A. (2020) Medical Exposure and Risk Estimation during Routine Radio-Diagnostic Examinations in Agadir City in 2012. Journal of Radiation Research and Applied Sciences, 13, 68-72. https://doi.org/10.1080/16878507.2019.1695382

[12] Semghouli, S., Amaoui, B., El Kharras, A., Bouyakhlef, K., Hakam, O.K. and Choukri, A. (2017) Establishment of a Diagnostic Reference Level for Brain CT Procedures in Moroccan Hospitals. International Journal of Advanced Research, 5, 319-324.

https://doi.org/10.21474/IJAR01/4114

[13] Semghouli, S., Amaoui, B., El Kharras, A., Bouykhlaf, K., Hakam, O.K. and Choukri, A. (2019) Evaluation of Radiation Risks during CT Brain Procedures for Adults. Perspectives in Science Journal, 12, Article ID: 100407. https://doi.org/10.1016/j.pisc.2019.100407

[14] Semghouli, S., Amaoui, B., Hakam, O.K. and Choukri, A. (2020) Radiation Exposure during Pelvimetry CT Procedures in Ibn Sina Children's Hospital of Rabat. Radiation Physics and Chemistry, 175, Article ID: 108087.

https://doi.org/10.1016/j.radphyschem.2018.12.007

[15] Amaoui, B., Semghouli, S., Massaq, M., Aabid, M., Hakam, O.K., Choukri, A. and El Kharras, A. (2019) Radiation Doses from Computed Tomography Practice in Regional Hospital Center Hassan II of Agadir, Morocco. Indian Journal of Public Health Research \& Development, 10, 629-632. https://doi.org/10.5958/0976-5506.2019.02883.3

[16] Aabid, M., Semghouli, S., Amaoui, B., El Fahssi, M., Hakam, O. and Choukri, A. (2019) Assessment of Radiation Risks during Brain CT Procedures in Moroccan Hospitals. Indian Journal of Public Health Research \& Development, 10, 713-718. https://doi.org/10.5958/0976-5506.2019.02898.5 
[17] Salama, D.H., Vassileva, J., Mahdaly, G., Shawki, M., Salama, A., Gilley, D. and Rehani, M.M. (2017) Establishing National Diagnostic Reference Levels (DRLs) for Computed Tomography in Egypt. Physica Medica, 39, 16-24. https://doi.org/10.1016/j.ejmp.2017.05.050

[18] Shirazu, I., Mensah, Y.B., Schandorf, C. and Mensah, S.Y. (2017) Estimate of Reference Effective Dose and Renal Dose during Abdominal CT Scan for Dose Optimization Procedures in Ghana. International Journal of Scientific \& Technology Research, 6, 215-224.

[19] Sulieman, A., Elnour, A., Mahmoud, M.Z., Alkhorayef, M., Hamid, O. and Bradley, D.A. (2020) Diagnostic Reference Level for Computed Tomography Abdominal Examinations: A Multicentre Study. Radiation Physics and Chemistry, 174, Article ID: 108963. https://doi.org/10.1016/j.radphyschem.2020.108963 